\title{
Erratum to: Is There a Super-Selection Rule in Quantum Cosmology?
}

\section{E. Sergio Santini ${ }^{1,2}$}

${ }^{1}$ CNEN-Comissão Nacional de Energia Nuclear,

Rua General Severiano 90, Botafogo 22290-901, Rio de Janeiro, Brazil

${ }^{2} \mathrm{CBPF}$-Centro Brasileiro de Pesquisas Físicas,

Rua Xavier Sigaud, 150, Urca, CEP 22290-180, Rio de Janeiro, Brazil

Received February 10, 2021; revised February 10, 2021; accepted February 12, 2021

DOI: $10.1134 / \mathrm{S} 0202289321020055$

A small graphic error has been detected in Figure 11 in [1], which must be replaced by the following one, with the same caption:

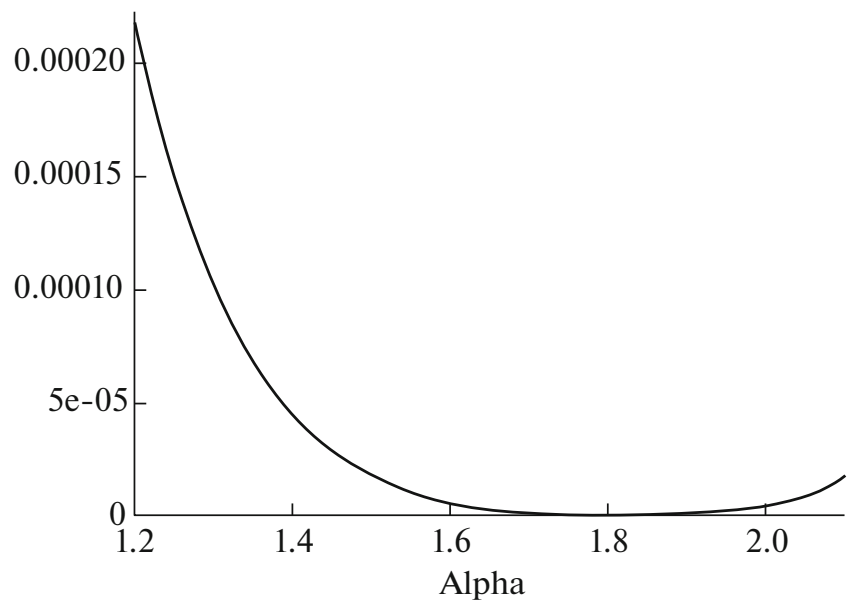

Fig. 11. The minimum of the effective potential for $\sigma=0.7$ is now at $\alpha=1.795$, i.e, it has moved away from the node which remains fixed at $\alpha=2.22$.

The original article can be found online at https://doi.org/10.1134/S0202289319030101

\section{REFERENCES}

1. E. Sergio Santini, "Is there a super-selection rule in quantum cosmology?" Grav. Cosmol. 25 (3), 226-236 (2019). 